\title{
Temporal and Spatial Dynamics of Primary and Secondary Infection by Armillaria ostoyae in a Pinus pinaster Plantation
}

\author{
Brigitte Lung-Escarmant and Dominique Guyon
}

First author: INRA-Bordeaux, and second author: UMR Santé Végétale, Unité de Bioclimatologie, BP81, 33883 Villenave d'Ornon cedex, France.

Accepted for publication 8 September 2003.

\begin{abstract}
Lung-Escarmant, B., and Guyon, D. 2004. Temporal and spatial dynamics of primary and secondary infection by Armillaria ostoyae in a Pinus pinaster plantation. Phytopathology 94:125-131.

Epidemiological investigations were performed in a 3-ha maritime pine (Pinus pinaster) plantation established on a site heavily infested by Armillaria ostoyae. Geostatistics were used to examine the density and the distribution of the initial inoculum. Disease dynamics were monitored for 17 years after planting. On the whole site, the cumulative mortality rate reached $35 \%$ over this period, plateauing at 12 years. Disease progress curves differed according to the density of the initial inoculum, although in all the cases, the Gompertz model described the epidemics

nized stumps) and secondary inoculum (newly dead pines) were evaluated by analyzing their spatial relation to annual mortality. Newly dead pines acted as secondary inoculum from year 3 and their role increased with time. When the initial inoculum density was low, the contribution of secondary inoculum to epidemic development increased faster and halted sooner than when the density of primary inoculum was high. Regardless of its density, the primary inoculum acted throughout the dynamic phase of the epidemic. When the inoculum density was low, the probability of mortality during the first 6 years of the epidemic depended on the tree distance from the nearest stumps colonized by Armillaria sp. When the inoculum density was high, the probability of mortality was higher and not related to the distance between trees and colonized stumps.
\end{abstract} well. The epidemiological contributions of both primary (initially colo-
Armillaria spp. are generally considered natural components of wood degrading mycoflora. Some of them, however, also cause root disease in natural and artificial forests in different parts of the world $(11,13)$ leading to serious economic losses due to mortality and growth reduction. Armillaria ostoyae, the predominant Armillaria sp. in conifers in the Northern Hemisphere, is the major cause of mortality of maritime pine (Pinus pinaster) in the Landes de Gascogne forest (Southwest France). In the middle of the 19th century, this coniferous forest was increased in size and today covers nearly 1 million ha. Dedicated to the production of wood, it is managed with intensive silvicultural methods. Stands are established by sowing or planting after land preparation and fertilization. Trees are clear felled at age 50 to 60 years. Understory clearing practices are conducted after establishment and before the periodic thinning operations; the first commercial thinning takes place in the second decade of the stand. Currently, serious economic losses result from tree mortality provoked by Armillaria root disease. In young stands, mortality is scattered (9). In older stands, the disease may progress with the formation of Armillaria disease foci (20). In adult stands, the progression of Armillaria disease foci can be intermittent as described in other conifer forests and with other root rot pathogens $(8,32)$. Little is known about the occurrence and the behavior of disease foci in mature stands and their relationships with the mortality that occurs in a young stand. There have been very few studies on the dynamics of Armillaria spp. over a long period. Van der Pas (30) and Swift (28) recorded mortality rates in young pine plantations in New Zealand and Zimbabwe, respectively. More recently, Bruhn et al. (3) and Hughes and Madden (12) have described the spatial and temporal

Corresponding author: B. Lung-Escarmant; E-mail address: lung@bordeaux.inra.fr

Publication no. P-2003-1124-01R

(C) 2004 The American Phytopathological Society patterns of Armillaria root disease in Ontario (Canada) on 10-year-old black spruce.

As a general rule, once Armillaria root rot becomes established on a site, it persists for many years, and throughout many rotations, surviving as a saprophyte after clear fell in the residual roots and stumps (26). Unlike most pathogenic fungi in the aboveground organs of plants, infection of young seedlings can occur quickly by direct contact of the growing roots with colonized residual root material, which constitutes the primary inoculum. Infected and decayed trees in the new plantation can become a secondary source of inoculum and the pathogen spreads by successively infecting neighboring trees. These two types of Armillaria inoculum have been described in various forest ecosystems $(11,23)$, but few experiments have temporally analyzed their respective roles in a specific stand.

The aim of the present study was to describe disease progression during the first 2 decades after planting in relation to the spatial distribution of inoculum and the density of the initial inoculum in order to better understand (i) the epidemiology of $A$. ostoyae in young maritime pine stands from planting to the first thinning and (ii) the relative contributions of primary and secondary inoculum to the dynamics of the epidemic.

\section{MATERIALS AND METHODS}

Experimental design. The experimental stand was located in the coastal part of the Landes de Gascogne forest at Contis (Department of Landes). The study was carried out in a 3-ha infested site with very poor, acidic and sandy soil. The plantation was established after cutting a 10-year-old maritime pine stand owing to the high level of tree mortality provoked by A. ostoyae. This 10-year-old stand followed a 60-year-old stand also heavily damaged by Armillaria root disease. In 1983, after clear-cutting the 10-year-old stand, an Armillaria inoculum map was prepared. In 1984, a plantation of 1-year-old maritime pine was established 
with $2-\times 4-\mathrm{m}$ spacing, which is the spacing commonly used in the Landes de Gascogne forest. On the whole site, 3,876 trees were planted in 76 rows without land preparation before planting. After planting, understory clearing practices commonly used in the Landes de Gascogne forest were applied annually for 5 years.

Data collection. Before planting, initial Armillaria inoculum was recorded by plotting the presence of Armillaria root rot in 10- and 60-year-old stumps of maritime pine and undergrowth shrubs (principally oaks, Quercus pedunculata, and Q. suber). Stumps were considered to be colonized by Armillaria spp. when the typical mycelial fans of the fungus were found under the bark of stumps or proximal part of the main roots. Ten years after cutting, the 60-year-old pine stumps were not fully decomposed. In autumn 1983, the presence of basidiocarps on the majority of the pine stumps and on a few oak stumps allowed the identification of the species present as A. ostoyae. The locations of the maritime pine and oak stumps, colonized and noncolonized by $A$. ostoyae, were recorded in a geographic database (Fig. 1).

In the experimental plantation, the health status of each tree (dead or alive) was recorded annually, in winter, from 1985 to 2001. At each assessment, all cases of mortality (A. ostoyae and other causes) were systematically recorded. The presence of mycelial fans under the bark at the root collar of a recently killed or dying sapling confirmed the causal association of Armillaria root disease with mortality. In the absence of characteristic Armillaria mycelial fans, other causes of mortality were noted: establishment failure, damage by windthrow, attacks of Dioryctria sylvestrella, and opportunistic pests such as Pissodes notatus and Ips sexdentatus. The locations of planted trees and their annual health status were recorded in the geographic database (Fig. 2).

Data analysis. To describe the spatial distribution of initial Armillaria inoculum, a simple index of primary contamination (PCI) was calculated from the presence or absence of Armillaria fans on the residual pine and oak stumps. Geostatistics were used to quantify PCI. A value of 0 denoted a noncolonized stump and a value of 1 indicated a colonized stump. The experimental variogram was estimated on the entire site and fitted to a spherical model. Kriging was then performed to estimate PCI on a regular grid of $1-\mathrm{m}^{2}$ units. Inoculum density was described from the spatial estimation of PCI.

The temporal progress of Armillaria disease was quantitatively described by counting surviving trees and trees killed by $A$. ostoyae every year. The disease progress curves were modeled by monomolecular, Gompertz, and logistic functions (5,31). These models, first applied to foliar diseases, have already been used in forest pathology for soilborne pathogens $(3,24,28)$. The exponential form of each model was fitted by nonlinear regression with the NLIN procedure (SAS Institute, Cary, NC) by minimization of the error sum of squares with the Gauss-Newton method. The fit of the model was assessed by analyzing residuals between observed data and predicted values.

To spatially characterize the epidemic, the distances of surviving and dead trees to the nearest primary and secondary Armillaria inoculum were calculated for each year. Distances from the nearest noncolonized stump were also estimated in order to better characterize the effect of the location of the initial inoculum.

The sensitivity of disease expression to the spatial distribution of the inoculum was analyzed with a generalized linear model. The link function between tree response and inoculum variables is a logistic function. $Y_{i}$ is the response of the tree, $i: Y_{i}=1$ if the tree is killed by $A$. ostoyae during year, $t$; and $Y_{i}=0$ if the tree is surviving at the end of year, $t . P$ is the probability that $Y_{i}=1$, and $1-P$ is the probability that $Y_{i}=0$.

For each year of observation, the model has the following form:

$$
\log \left(\frac{P}{1-P}\right)=\beta_{0}+\beta_{1} X_{1}+\beta_{2} X_{2}+\beta_{3} X_{3}
$$

in which $X_{1}$ is the distance from the nearest colonized stump (primary inoculum), $X_{2}$ is the distance from the nearest noncolonized stump, and $X_{3}$ is the distance from the nearest tree killed by $A$. ostoyae during the previous years (secondary inoculum). $X_{k}$ is expressed in meters.

$X_{2}$ was used to partially compensate for the weaknesses of the $X_{1}$ variable to spatially sample the initial inoculum. $X_{1}$ is the distance from the center of the nearest colonized stump and not from the nearest colonized root. Moreover, it does not take into account the azimuth direction of this potential source of inoculum around the tree. For these reasons, and because of the clustered pattern of primary inoculum, $X_{1}$ and $X_{2}$ were not correlated in the same way on the entire site, even though $X_{2}$ generally decreased when $X_{1}$ increased. For example, a tree located at the edge of a cluster of colonized stumps could show low values of both variables $X_{1}$ and $X_{2}$.

The model was fitted by the method of maximum likelihood with the LOGISTIC procedure of SAS. The quality of the

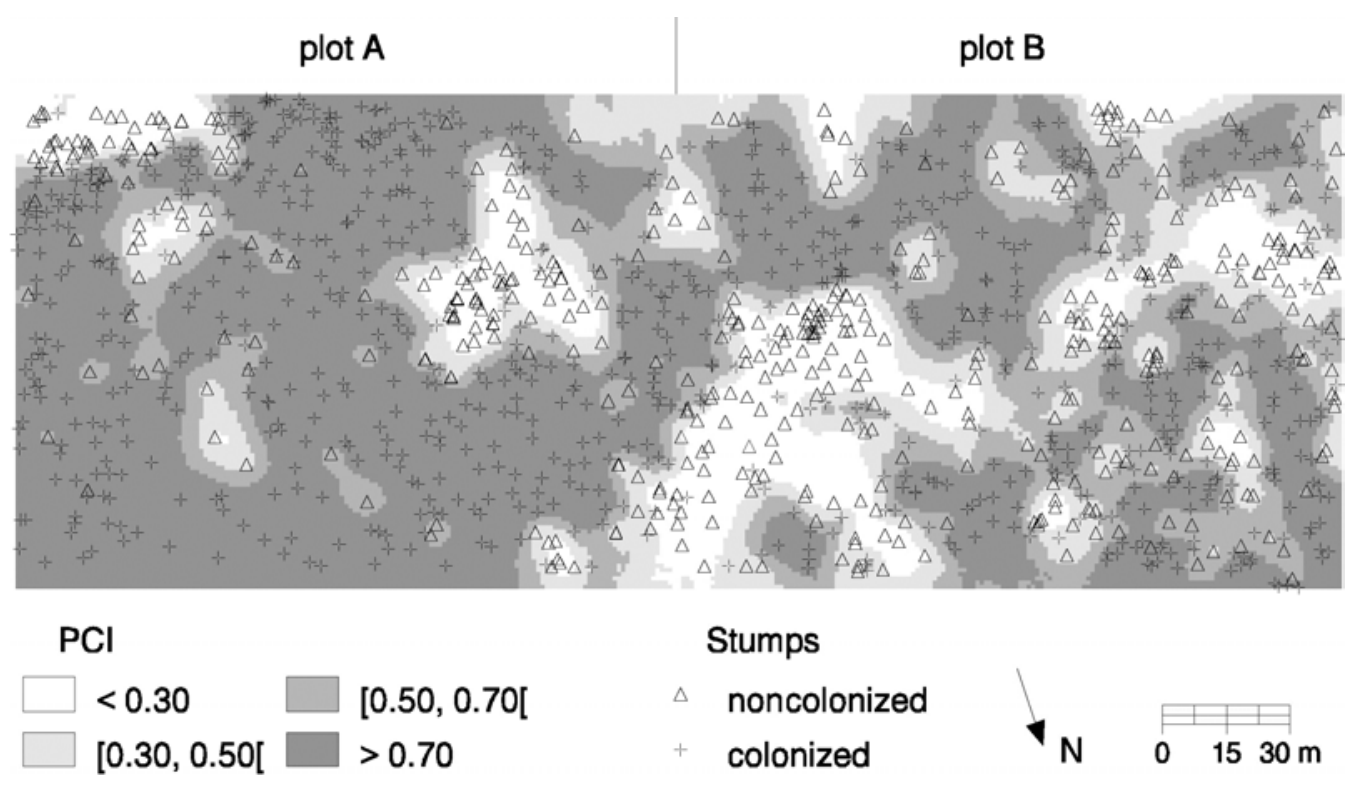

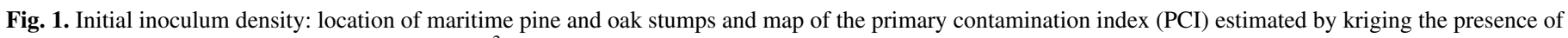
Armillaria spp. on stumps on a regular grid of $1-\mathrm{m}^{2}$ units. 
estimation of parameters $\beta_{k}$ was assessed with the test of Wald. If the probability $\left(\beta_{k}=0\right)>$ alpha, we considered $\beta_{k}=0$. We used a value of alpha equal to 0.10 . In order to make interpretation easier, the exponential transformation was used: $b_{k}=\exp \left(\beta_{k}\right)$. Hence, $b_{k}$ reveals the sensitivity of $P / 1-P$ to an increase of $X_{k}$ equal to $1 \mathrm{~m}$. If $b_{k}$ is $=1$, the variable does not have any effect. If $b_{k}$ is $>1$, the probability of mortality decreases and if $b_{k}$ is $<1$, the probability increases.

The ARC/INFO GIS software (release 8.0.2, UNIX, 2000, ESRI, Redlands, CA) was used to calculate the distances between surviving or dead trees and different Armillaria inoculum sources and for geostatistics. The statistical analyses were performed using the SAS statistical software package (release 8.1, SAS Institute).

\section{RESULTS}

Initial inoculum density. About 1,300 stumps were recorded on the entire 3-ha site (433 stumps per ha) and were categorized as follows: $58 \%$ 10-year-old maritime pine, $23 \%$ 60-year-old maritime pine, $15 \%$ Q. pedunculata, and $4 \%$ Q. suber. Among them, $63 \%$ were colonized by A. ostoyae with an equal proportion in each category of stumps. The calculation of PCI confirmed that the experimental site was heavily infested (Fig. 3: total median PCI $=0.71$ ) but inoculum was spatially heterogeneous, as revealed by the variogram range value (approximately $21 \mathrm{~m}$ ) and Figure 1 . The heavily infested area (PCI $>0.71)$ included large patches up to 1 ha, mostly situated in the eastern half of the site. The patches with less inoculum $(\mathrm{PCI}<0.30)$ were smaller and were not randomly distributed over the site, the majority of them being in the western half of the site. Consequently, the two halves of the 3-ha site differed strongly in regard to spatial distribution (Fig. 1) and density (Fig. 3) of the initial inoculum. The eastern half of the site (plot A) was characterized by a high level of initial inoculum (median PCI $=0.82$ ): $65 \%$ of the surface of the eastern area (approximately 1 ha) was heavily infested (PCI $>0.71$ ), mixed with less infested patches $(35 \%$ of the surface with PCI $<$ 0.71). The western half of the site (plot B) was characterized by a medium level of initial inoculum (median PCI $=0.58$ ): $66 \%$ of the area (approximately $1 \mathrm{ha}$ ) was moderately infested (PCI < $0.71)$ with small heavily infested patches scattered throughout the plot $(34 \%$ of the surface with PCI $>0.71)$.

Temporal dynamics of the epidemic. The rate of temporal disease progress over the entire site is shown in Figure 4A. Deaths caused by Armillaria root disease were first observed in the field trial 1 year after planting $(0.6 \%)$. The mortality caused by $A$. ostoyae reached $34.5 \%$ over the 17 -year period. The cumu- lative mortality rate increased greatly during the first 6 years (phase 1, corresponding to $76.5 \%$ of the total number of dead trees recorded during the entire survey), dropped dramatically during the next 5 years (phase 2, years 7 to 11), and reached a plateau during the last period (phase 3 , years 12 to 17 ), indicating a weakening of the epidemic. The annual mortality rate estimated in year 12 was 20 times lower than that calculated in year $6\left(\chi^{2}\right.$, $P<0.0001)$.

These three phases of the epidemic were also observed in areas of the plantation with a different density of initial inoculum (Fig. 4B). Epidemiological differences were noted between plots A and $\mathrm{B}$ however. Final mortality levels ranged from $32 \%$ (plot B) to $40 \%$ (plot A) and were significantly different $\left(\chi^{2}, P<0.0001\right)$. Disease progress curves mainly differed during the second phase of the epidemic. From years 7 to 11, the cumulative mortality rate increase in plot A was twice that in plot B. This increase in mortality was clearly evident from the minor additional peaks observed in the annual mortality rates in plot A.

In all cases, disease progress curves seemed to fit the Gompertz model (Fig. 4). Analyses of residuals between observed data and predicted values showed that data were better described by the Gompertz function than a logistic function (Table 1). If the coefficients of determination were very high for the two cases $\left(R^{2}>0.99\right)$, square root of mean of residual squares (RMSE) were generally higher with the logistic than with the Gompertz model.

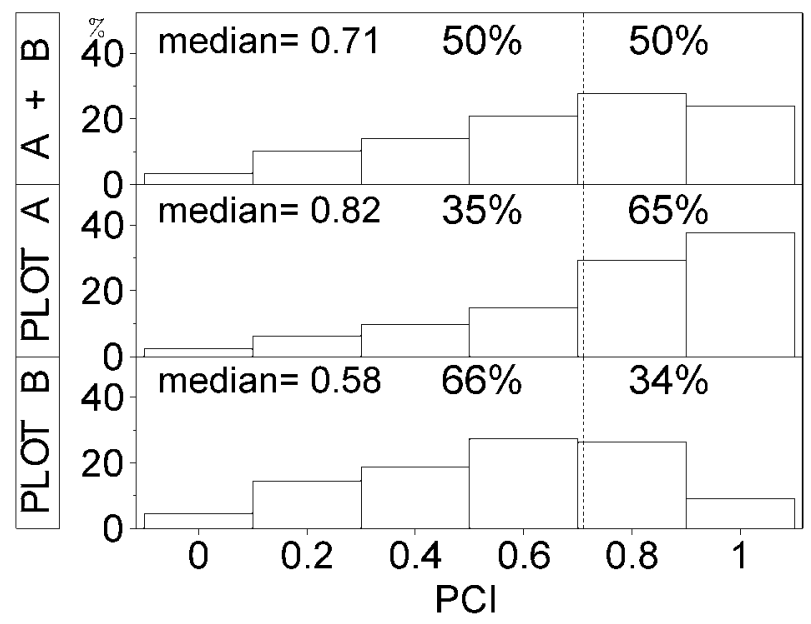

Fig. 3. Distribution of primary contamination index (PCI) in the whole site and in the two halves of the site: plot $\mathrm{A}=$ eastern half of the site; and plot $\mathrm{B}=$ western half of the site. $y$ axis indicates percent surface.

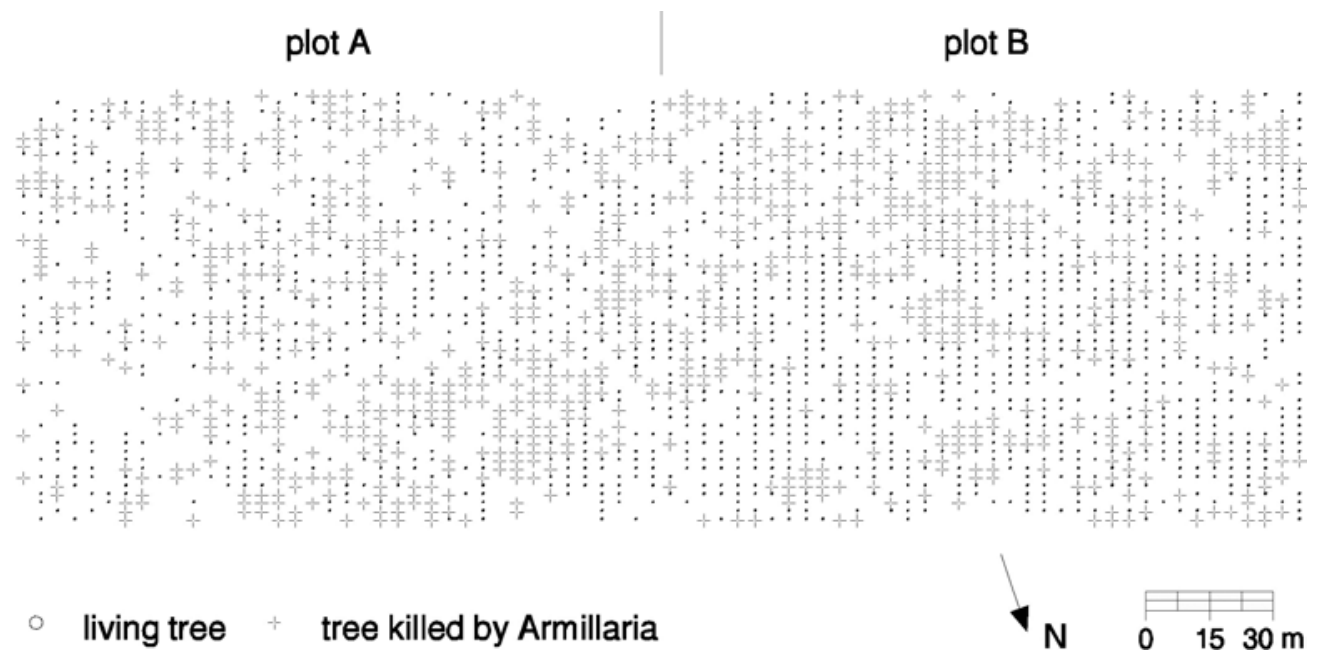

Fig. 2. Location of dead and surviving trees 17 years after planting. 
Regardless of the area of the site analyzed, the monomolecular model was less appropriate to describe these sigmoid curves $\left(R^{2}<\right.$ 0.97 ; RMSE > 0.002). Differences between progress curves in relation to the initial inoculum density were confirmed by the Gompertz apparent mortality rate $(r)$ which was significantly lower in plot A than in plot $\mathrm{B}(P<0.0001)$.

Spatial characteristics of the epidemic. The spatial distribution of dead trees in relation to the nature of the nearest inoculum was analyzed first (Fig. 5). During the first phase of the epidemic, the majority of saplings dying each year were those nearest to the primary inoculum. This proportion of trees nearest to the primary inoculum decreased with time, while the proportion of dying trees nearest to the secondary inoculum increased. In the second phase of the epidemic, the distributions of the tree distances from the two types of inoculum were equivalent. In the third phase, the spatial distribution was completely random, with the infrequent
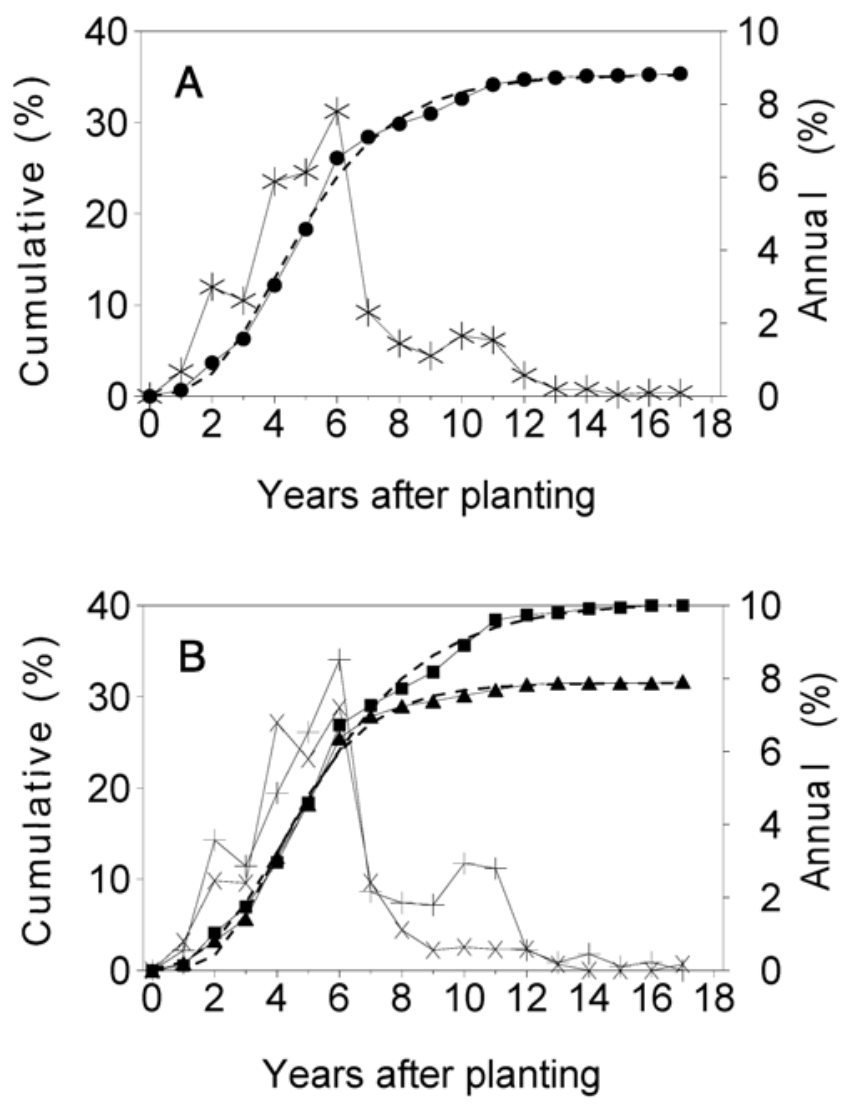

Fig. 4. Temporal pattern of Armillaria mortality on A, the whole site ( cumulative mortality rate; ---, curve fitted to Gompertz model; and $*$, annual mortality rate) and $\mathbf{B}$, the two plots with contrasted density of initial inoculum (solid symbols, cumulative mortality rate; cross symbols, annual mortality rate; $\boldsymbol{\square}$ and + , site heavily infested (plot $A$ ); $\boldsymbol{\Delta}$ and $\times$ : site moderately infested (plot B); and ---, curves fitted to Gompertz model.

TABLE 1. Parameter estimates and residual deviances for fitting of temporal progress $^{\mathrm{a}}$

\begin{tabular}{lcccc}
\hline Models & $r$ & $K$ & $R^{2}$ & RMSE \\
\hline $\begin{array}{l}\text { Logistic model } \\
\text { Whole site }\end{array}$ & $0.745(0.048)$ & $0.345(0.004)$ & 0.995 & 0.0098 \\
Plot A & $0.612(0.046)$ & $0.392(0.006)$ & 0.992 & 0.0138 \\
Plot B & $0.899(0.039)$ & $0.311(0.002)$ & 0.998 & 0.0056 \\
Gompertz model & & & & \\
Whole site & $0.483(0.024)$ & $0.352(0.003)$ & 0.997 & 0.0074 \\
Plot A & $0.399(0.022)$ & $0.403(0.005)$ & 0.996 & 0.0095 \\
Plot B & $0.595(0.031)$ & $0.315(0.003)$ & 0.997 & 0.0066 \\
\hline
\end{tabular}

a $r$ apparent annual mortality rate, $K=$ asymptote of the curve of cumulative mortality: asymptotic standard error in brackets. RMSE $=$ square root of mean of residual squares. new dead trees (maximum of four per year) being alternatively nearest to the primary or secondary inoculum.

The distribution of distances of all the trees from the two types of inoculum (initially colonized stumps or newly dead trees) confirmed the first analysis (Table 2). During the first phase of the epidemic (from years 1 to 6 ), the mean distance of dead trees from primary inoculum increased slightly and was lower $(<3 \mathrm{~m})$ than the mean distance from secondary inoculum. The latter decreased sharply from 17 to $4 \mathrm{~m}$. In the second phase of the epidemic (from years 7 to 11), the mean distances of dead trees from the two types of inoculum were similar (approximately $3 \mathrm{~m}$ in both cases). Surviving trees were on average always further from colonized stumps or trees and always nearer to noncolonized stumps than dead trees. Mean distances of surviving and dead trees from the primary inoculum differed slightly (close to 3.5 and $3.0 \mathrm{~m}$, respectively). These results were enhanced by analyzing the probability of mortality in relation to the spatial distribution of noncolonized and colonized stumps as primary inoculum and newly dead trees as secondary inoculum (Fig. 6A). Three stages in temporal variation of estimated parameters $b_{1}, b_{2}$, and $b_{3}$ were described in the two active phases observed in the temporal curves (from years 1 to 11): (i) during the first 3 years, the probability of mortality was related only to the tree distance to the primary inoculum $\left(b_{1}\right.$ and $\left.b_{2} \neq 1 ; b_{3}=1\right)$; (ii) from years 3 to 6 , the contribution of the primary inoculum decreased, while that of the secondary inoculum increased; and (iii) from years 7 to 11, secondary inoculum became the principal active type of inoculum $\left(b_{1}=1 ; b_{2}\right.$ and $\left.b_{3} \neq 1\right)$. In this third stage, the contribution of the primary inoculum was actually still important due to the fact that the probability of mortality was still influenced by the distance of the tree to the noncolonized stumps $\left(b_{2} \neq 1\right.$, maximum value $=$ 1.2). This result indicates that mortality always occurred in the initially infested zones. After 11 years, the number of trees killed each year was very low and their spatial distribution was completely random $\left(b_{1}=b_{2}=b_{3}=1\right)$.

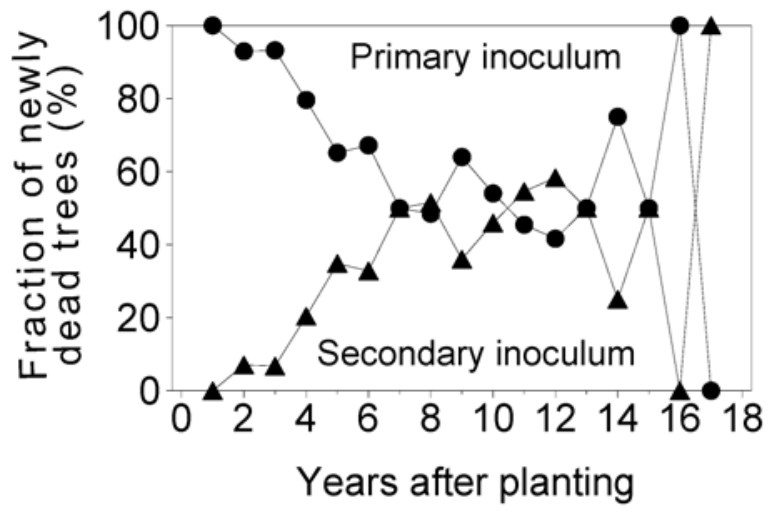

Fig. 5. Distribution of annual mortality in relation to the nature of the nearest inoculum type: $\boldsymbol{\bullet}$, primary inoculum; and $\boldsymbol{\Delta}$, secondary inoculum.

TABLE 2. Temporal change of mean distance (in meters) of dead trees and surviving trees from the nearest primary inoculum source (initially colonized stumps) and from the nearest secondary inoculum (newly dead trees) ${ }^{\mathrm{a}}$

\begin{tabular}{llrllll}
\hline & \multicolumn{6}{c}{ Year } \\
\cline { 2 - 7 } Distances & \multicolumn{1}{c}{1} & \multicolumn{1}{c}{2} & 3 & 6 & 7 & 11 \\
\hline Distance of dead trees from & & & & & & \\
$\quad$ Primary inoculum & 2.49 & 2.82 & 3.04 & 2.98 & 3.13 & 3.26 \\
$\quad$ Secondary inoculum & - & 17.59 & 8.57 & 3.95 & 3.39 & 3.01 \\
$\quad$ Noncolonized stumps & 6.97 & 7.29 & 6.24 & 6.70 & 6.97 & 8.15 \\
Distance of surviving trees from & & & & & & \\
$\quad$ Primary inoculum & 3.48 & 3.50 & 3.50 & 3.64 & 3.65 & 3.69 \\
$\quad$ Secondary inoculum & - & 19.45 & 9.52 & 5.26 & 4.65 & 4.28 \\
$\quad$ Noncolonized stumps & 5.70 & 5.64 & 5.6 & 5.26 & 5.17 & 4.92 \\
\hline
\end{tabular}

a Comparison with the mean distance from the nearest noncolonized stump. 
The same analysis was conducted in the two plots presenting different initial inoculum densities. In this case, when the disease progressed very slowly (in plot A after the 12th year and in plot B after the 10th year), the annual mortality frequency was not sufficient to calculate the parameters with satisfactory accuracy. Differences appeared in relation to the initial inoculum density (Fig. 6B and C). The trends described for the entire site were observed during the first 8 years of the epidemic in the initially moderately infested plot B (Fig. 6B). Some differences to these trends were observed in plot A (Fig. 6C). In the latter case, the probability of mortality was not dependent on tree distance to initially colonized stumps $\left(b_{1}=1\right.$ regardless of the year of the epidemic). Indeed, in plot A, 75\% of the trees dead over an 11 -year period were nearer to primary inoculum than to secon-
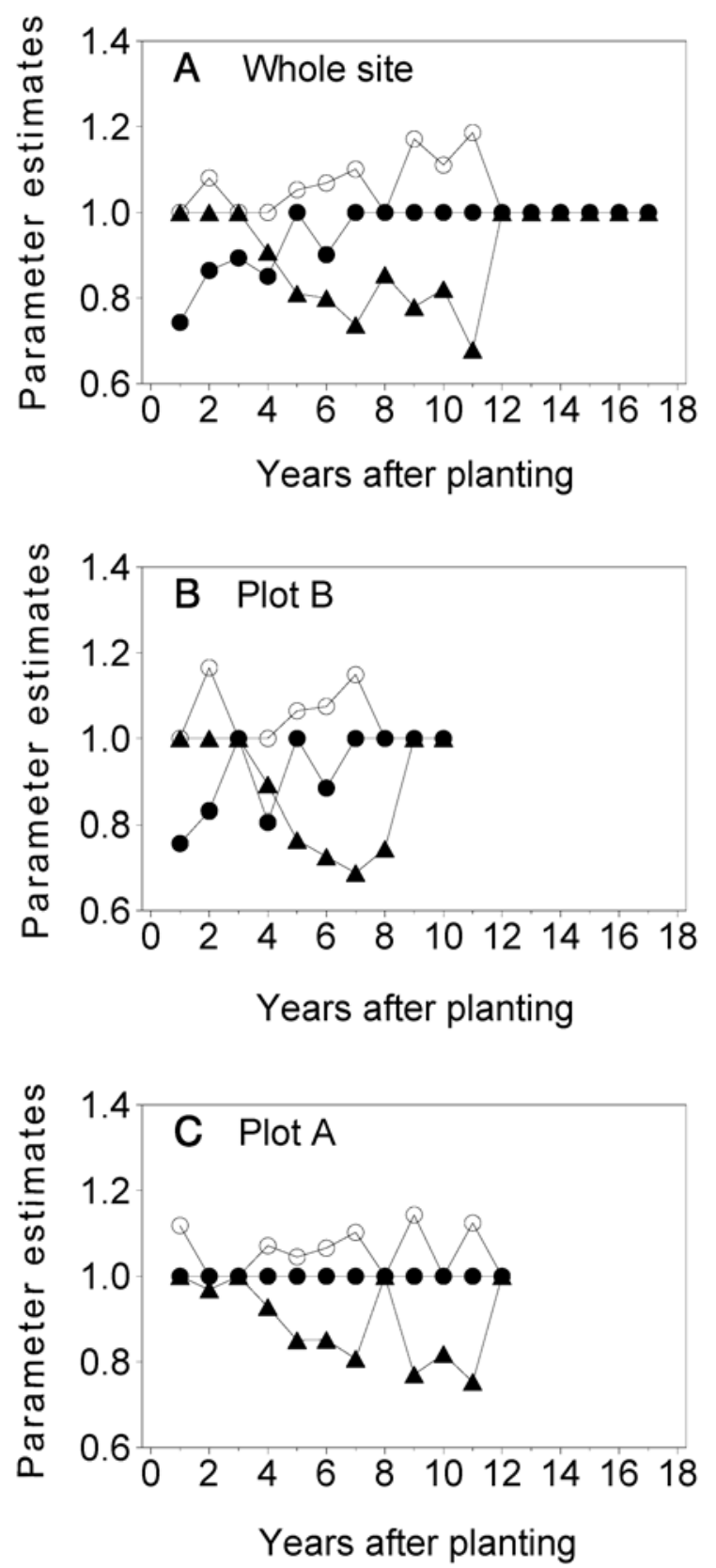

Fig. 6. Sensitivity of probability of mortality to the spatial distribution of primary and secondary inoculum on $\mathbf{A}$, the whole site; $\mathbf{B}$, half of the site initially moderately infested (plot B); and $\mathbf{C}$, half of the site initially highly infested (plot A). - and $\mathrm{O}=$ distance from the stumps of the former stand as primary inoculum $\left(\bullet=\right.$ colonized stumps (parameter $\left.b_{1}\right) ; \bigcirc=$ noncolonized stumps [parameter $\left.\left.b_{2}\right]\right)$; and $\boldsymbol{\Delta}=$ distance from the newly dead trees as secondary inoculum (parameter $b_{3}$ ). dary inoculum (Fig. 7). The proportion of dead pines with primary inoculum as the nearest source was always higher in plot $\mathrm{A}$ (high inoculum density) than in plot B (medium inoculum density). Inversely, the proportion of dead pines with secondary inoculum as the nearest source was always higher in plot B.

\section{DISCUSSION}

Initial inoculum density. The different sources of inoculum considered in this study were the initially colonized stumps (primary inoculum) and the newly dead trees (secondary inoculum). Basidiospores and rhizomorphs as sources of inoculum were not taken into account. The role of A. ostoyae basidiospores in both the infection of healthy trees and the colonization of healthy stumps is dubious (26). Armillaria spp. produce few rhizomorphs in acidic sandy soils (25). On maritime pine, rhizomorphs were found at the root collar and at the infection points of root-to-root contacts as described on lodgepole pine in Alberta (14). In this study, we consider rhizomorphs to play a major role in the infection process, but this role was spatially limited to the rhizosphere from which the rhizomorphs originated. Oak substrate actually promotes rhizomorph production and infection in A. ostoyae (26). We therefore consider that colonized stumps mapped before planting were the main sources of primary inoculum in the site.

The reservoir of inoculum in the soil before planting is a critical component in the expression of Armillaria disease. This is the first time that geostatistics have been used to estimate initial inoculum density, but this parameter was difficult to quantify because the radial extension of root volume around each stump was not measured. There is little information about the root system architecture of pine and oak species. According to Danjon et al. (6), the maximal root radial extension of young pines (5 years old) is approximately equal to stem height and reaches far beyond the midpoints between neighboring trees in a $2-\times 4$-spacing plantation. With a density of 377 stumps per hectare from the 60and 10-year-old pine trees of the previous stands, we calculated that the mean distance from stump to stump was $5.5 \mathrm{~m}$, corresponding to the mean height of 10 -year-old maritime pine in the poorly productive sandy soil of the southwest pine forest (15). Consequently, in our analyses, we assumed that the roots around stumps colonized the entire superficial soil layer whatever the stump species and that the inventory of stumps was actually a random sampling of the presence of inoculum in soil.

The calculation of PCI allowed stratification of the site according to the density of inoculum. Division according to the PCI

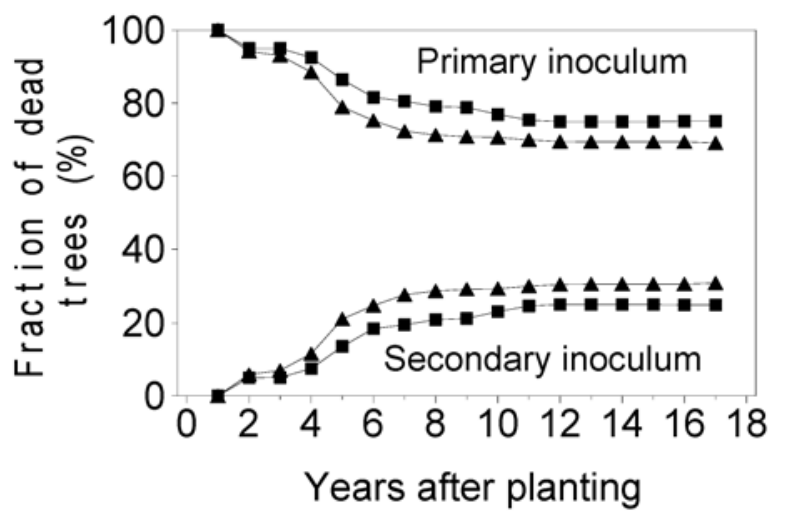

Fig. 7. Distribution of cumulative mortality in relation to the nature of the nearest inoculum type on the two plots presenting a different density of primary inoculum. -, plot A highly infested; and $\mathbf{\Lambda}$, plot B moderately infested. In each plot, fraction of trees nearest to the primary inoculum (high part of the graph) + fraction of trees nearest to the secondary inoculum (low part of the graph) $=100 \%$. 
values (i.e., great than or less than the median) was not performed, because it did not allow spatial analyses owing to the fragmentation of the less infested areas. The two plots (plots A and B), forming two continuous halves of the site with different inoculum density, were suitable for spatial analyses and reflected the patchy nature of the Armillaria inoculum found in maritime pine stands.

Temporal dynamics of the epidemic. Three main phases characterized this epidemic: (i) an exponential increase in mortality rate during the first 6 years after planting, (ii) a decrease in rate to the 11th year, and (iii) a plateau until the 17th year. This temporal disease progression fitted the Gompertz model and a logistic model better than a monomolecular model. In other studies, while a logistic model described Armillaria disease progress curves on slash pine in Rhodesia (28), a monomolecular function was more appropriate for epidemics in other pine plantations $(4,30)$ and black spruce seed orchards $(3)$. However, in the latter studies, the epidemics were only analyzed for relatively short periods of time (from 4 to 10 years) and were probably terminated before the end of the dynamic phase of the epidemic. The preliminary analyses of temporal disease progression carried out at different periods of time after planting for our experimental site at Contis showed differences in the fit of progress curves to the models. In the first analysis conducted 5 years after the beginning of the epidemic, mortality progress curves fitted the monomolecular model better than the logistic model (18). In the second analysis conducted after 12 years, at the end of the second phase of the epidemic, it was impossible to adjust any model without dividing the disease progress curves into two periods. These two parts of the curve were separately better fitted to the logistic model than to the monomolecular one (17). In the present analysis conducted after 17 years, the Gompertz model described the epidemics better than the logistic model (the disease curves not being symmetrical around the inflection point). These different analyses underline the complexity of the processes involved in epidemic development. The development of any plant disease epidemic can be influenced by many distinct factors including climatic variation or cultural practices. This may explain difficulties in adjusting a model to the data. For example, in our study, the application of understory clearing practices annually over a 5 -year period after planting and a drought that appeared in years 5 to 6 probably contributed to the fluctuations in annual mortality rates during the first years of the epidemics (Fig. 4).

Spatial characteristics of the epidemic. To our knowledge, this study is the first to describe temporal dynamics of A. ostoyae in relation to the spatial distribution of the inoculum over a long period (17 years). Spatial analyses of Armillaria root disease on Douglas-fir in British Columbia (29), on Pinus mugo var. uncinata in Switzerland (7), or on black spruce in Ontario (12) were conducted from a static sample in time in order to describe the spatial pattern of the surviving and dead trees.

Our use of a geographic database and a spatial generalized linear model allowed distinction of the different inoculum sources and an analysis of their role in the spread of the disease. To analyze more precisely the extension of the disease, it will be necessary to explore more complex models integrating the tree root and fungal growth $(1,2,5)$. A root growth model would allow an analysis of the incidence of root-free spaces due to establishment failure of the pine trees 1 year after planting. Spatial analyses revealed that primary inoculum from residual colonized stumps is an important source of disease throughout the epidemic with secondary inoculum becoming increasingly effective with time.

Initial primary inoculum density played a major role in disease incidence. During the second phase of the epidemic, disease progress was marked and sustained in the part of the stand with a high primary inoculum density. This can be explained by the shorter distance between the stump inoculum and young trees, which increases the probability of contact between the fungus and its host. In plot A, the probability of contact was so high that the probability of mortality was not influenced by the distance of the trees to the colonized stumps of the former stand. The high density of primary inoculum contributed to its long duration of effectiveness and to its continuing role in the second phase of the epidemic. The secondary inoculum became significant during the last 3 years of the dynamic phase of the epidemic (years 8 to 11) as living trees were dramatically reduced in the highly infested zones (Fig. 2).

In contrast, in the initially less infested site (plot B), there was a relationship between probability of mortality and distance from the primary inoculum. In this case, the probability of root contact with the primary inoculum, lower in the first years after planting, increased with tree age as shown by the decreasing relationship from year 1 to 7 between probability of mortality and tree distance from primary inoculum.

The influence of secondary inoculum increased regularly from the third year after planting to the last year of the dynamic phase of the epidemic regardless of the initial inoculum density. Secondary inoculum, however, acted sooner and for a shorter period in the part of the site initially less infested (plot B). In this case, the roles of the primary and secondary inoculum during the effective phases of the epidemic (phases 1 and 2) were reversed and mutually counterbalanced, with the secondary inoculum allowing the disease progress to be maintained at a high level during the epidemic's first phase. After year 7, the probability of root contact with the primary inoculum was very low. Thus, the primary inoculum did not contribute to increases in disease intensity, and disease progress was halted in the second phase of the epidemic. Tree growth was probably insufficient to allow disease spread by root-to-root contact to healthy trees in initially less infested zones before the host reaction defenses took place.

Disease incidence. The primary pathogenicity of A. ostoyae in Pinus pinaster in the pine forest of the Landes de Gascogne is confirmed; when plantations are established on sites where the former stand was heavily damaged by $A$. ostoyae, this root rot fungus is capable of eliminating one third of the planted trees in the first 10 years of a stand. This level of damage is currently taking place in the coastal part of the pine forest of the Landes de Gascogne, which is the oldest part, and where the fourth-rotation stands were first established. A similar disease incidence was described by Self et al. (27) on Pinus radiata in New Zealand in first-rotation stands established on sites converted from indigenous forest. In this case, however, A. novae-zelandiae provoked a chronic Armillaria root disease mainly affecting the growth of infected trees.

The extension of Armillaria disease decreased over time. This can be attributed to the increase of root biomass and host defense reactions with age $(22,23)$. This is consistent with our earlier findings that 10- to 12-year-old maritime pine can effectively resist Armillaria infection (19) but are highly susceptible when young (21). Nevertheless, host defense reactions can be absent in mature maritime pine (19) and Armillaria disease can continue to cause tree death in 20- to 35-year-old stands of maritime pine as already observed by Lundquist (16) on Pinus elliottii in South Africa. Thus, it would be interesting to monitor this experiment over a longer period of time to determine the different phases of disease development over the entire rotation of maritime pine stands. In the same way, it would be useful to know the influence of thinning on disease progress as analyzed by Hood et al. (10) on Pinus radiata in New Zealand. To better explain the subsequent development of the disease in older pine plantations, it is necessary to know, at different ages of the stand, the influence of A. ostoyae on pine growth and the time required from infection by $A$. ostoyae to tree death. Further studies could provide a valuable aid to establishing a general model of Armillaria impact in Pinus pinaster plantations in Southwest France. 


\section{ACKNOWLEDGMENTS}

We thank B. Chauvin, G. Courrier, R. Germain, and A. Giraud for technical assistance and data collection, the staff of ONF (Office National des Forêts) for the establishment of experimental design and field maintenance, and M.-L. Desprez-Loustau, C. Mohammed, E. Hansen, B. Marçais, and the anonymous reviewers for critically reading this manuscript.

\section{LITERATURE CITED}

1. Bailey, D. J., and Gilligan, C. A. 1999. Dynamics of primary and secondary infection in take-all epidemics. Phytopathology 89:84-91.

2. Brown, T. N., Kulasiri, D., and Gaunt, R. E. 1997. A root morphology based simulation for plant-soil microbial ecosystem modelling. Ecol. Model. 99:275-287.

3. Bruhn, J. N., Mihail, J. D., and Meyer, T. R. 1996. Using spatial and temporal patterns of Armillaria root disease to formulate management recommendations for Ontario's black spruce (Picea mariana) seed orchards. Can. J. For. Res. 26:298-305.

4. Bruhn, J. N., Mihail, J. D., and Pickens, J. B. 1994. Spatial dynamics of Armillaria genets in Pinus resinosa plantations established on hardwood sites in northern Michigan. Pages 460-469 in: Proc. 8th Int. Conf. on Root and Butt Rots. M. Johansson and J. Stenlid, eds. Swed. Univ. Agric. Sci., IUFRO working party S2.06.01.

5. Campbell, C. L., and Madden, L. V. 1990. Introduction to Plant Disease Epidemiology. John Wiley \& Sons, New York.

6. Danjon, F., Bert, D., Godin, C., and Trichet, P. 1999. Structural root architecture of 5-year-old Pinus pinaster measured by 3D digitising and analyses with AMAPMOD. Plant Soil 217:49-63.

7. Dobbertin, M., Baltensweiler, A., and Rigling, D. 2001. Tree mortality in an unmanaged mountain pine (Pinus mugo var. uncinata) stand in the Swiss National Park impacted by root rot fungi. For. Ecol. Manag. 145:79-89.

8. Durrieu, G., Beneteau, A., and Niocel, S. 1985. Armillaria obscura dans l'écosystème de Cerdagne. Eur. J. For. Pathol. 15:350-355.

9. Guyon, D., Riom, J., and Taris, B. 1985. Study of the behaviour and spread of Armillaria obscura on maritime pine in the forest of the Landes, based on large-scale aerial photographs: Methods and preliminary results. (in French) Colloq. INRA 32:73-86.

10. Hood, I. A., Kimberley, M. O., Gardner, J. F., and Sandberg, C. J. 2002. Armillaria root disease of Pinus radiata in New Zealand. 3: Influence of thinning and pruning. N.Z. J. For. Sci. 32:116-132.

11. Hood, I. A., Redfern, D. B., and Kile, G. A. 1991. Armillaria in planted hosts. Pages 122-149 in: Armillaria Root Disease. C. G. Shaw and G. A. Kile, eds. U.S. Dep. Agric. Agric. Handb. For. Ser. 691.

12. Hughes, G., and Madden, L. V. 1998. Comment-using spatial and temporal patterns of Armillaria root disease to formulate management recommendations for Ontario's black spruce (Picea mariana) seed orchards. Can. J. For. Res. 28:154-158.

13. Kile, G. A., Mc Donald, G. I., and Byler, J. W. 1991. Ecology and disease in natural forests. Pages 102-121 in: Armillaria Root Disease. C. G. Shaw and G. A. Kile, eds. U.S. Dep. Agric. Agric. Handb. For. Ser. 691.

14. Klein-Gebinck, H., Blenis, P. V., and Hiratsuka, Y. 1991. Spread of Armillaria ostoyae in juvenile lodgepole pine stands in west central Alberta. Can. J. For. Res. 21:20-24.

15. Lemoine, B., and Decourt, N. 1969. Tables de production pour le pin maritime dans le sud-ouest de la France. Rev. For. Fr. 21(1):5-6.
16. Lundquist, J. E. 1993. Spatial and temporal characteristics of canopy gaps caused by Armillaria root disease and their management implications in lowveld forests of South Africa. Eur. J. For. Pathol. 23:362-371.

17. Lung-Escarmant, B., Guyon, D., Chauvin, B., Courier, G., and Germain, R. 1998. Spatial and temporal patterns of Armillaria root disease in a Pinus pinaster plantation: Incidence of understory clearing. Page 439 in: Proc. 9th Int. Conf. on Root and Butt Rot. C. Delatour, J. J. Guillaumin, B. Lung-Escarmant, and B. Marçais, eds. Colloq. INRA, IUFRO working party S2.06.01.

18. Lung-Escarmant, B., Guyon, D., and Taris, B., 1990. Recherche de l'impact de la sylviculture intensive sur l'expression des maladies racinaires: Cas particulier de l'Armillaire (A. ostoyae) en forêt des Landes de Gascogne. Colloq. ARBORA Bordeaux, Mai 1990:529-535.

19. Lung-Escarmant, B., Maugard, F., Giraud, A., Escrivant, M. A., Molinier, F., Merilleau, F., and Vida, G. 2002. Infectious cycle of Armillaria ostoyae on maritime pine stands of different ages. Pages 428-431 in: Proc. 10th Int. Conf. on Root and Butt Rot. G. Laflamme, J. A. Bérubé, and G. Bussières, eds. Nat. Resour. Can., Can. For. Ser., Laurentian For. Cen., IUFRO working party S2.06.01.

20. Lung-Escarmant, B., and Taris, B. 1985. L'Armillaire, parasite du Pin maritime dans les Landes de Gascogne. Eur. J. For. Pathol. 15:371-372.

21. Lung-Escarmant, B., and Taris, B. 1989. Methodological approach to assess host response (resinous and hardwood species) to Armillaria obscura infection in the Southwest French pine forest. Pages 226-236 in: Proc. 7th Int. Conf. on Root and Butt Rots. D. J. Morrison, ed. Minister of Supply and Service Canada, IUFRO working party S2.06.01.

22. MacKenzie, M. 1987. Infection changes and volume loss in a 19-year-old Pinus radiata stand affected by Armillaria root rot. N.Z. J. For. Sci. 17:100-108.

23. Morrison, D. J., Williams, R. E., and Whitney, R. D. 1991. Infection, disease development, diagnosis and detection. Pages 62-75 in: Armillaria Root Disease. C. G. Shaw and G. A. Kile, eds. U.S. Dep. Agric. Agric. Handb. For. Ser. 691.

24. Nandris, D., Nicole, M., and Geiger, J. P. 1988. Root-rot diseases of the rubber tree in the Ivory Coast. 1. Severity, dynamics and characterization of epidemics. Can. J. For. Res. 18:1248-1254.

25. Redfern, D. B. 1973. Growth and behaviour of Armillaria mellea rhizomorphs in soil. Trans. Br. Mycol. Soc. 61:569-581.

26. Redfern, D. B., and Filip, G. M. 1991. Inoculum and infection. Pages 4861 in: Armillaria Root Disease. C. G. Shaw and G. A. Kile, eds. U.S. Dep. Agric. Agric. Handb. For. Ser. 691.

27. Self, N. M., Hood, I. A., Kimberley, M., Shu, Q. L., and Gardner, J. F. 1988. Distribution and incidence of Armillaria root disease in Pinus radiata plantations throughout New Zealand. Pages 137-147 in: Proc. 9th Int. Conf. on Root and Butt Rot. C. Delatour, J. J. Guillaumin, B. LungEscarmant, and B. Marçais, eds. Colloq. INRA, IUFRO working party S2.06.01.

28. Swift, M. J. 1972. The ecology of Armillaria mellea (Vahl ex Fries) in the indigenous and exotic woodlands of Rhodesia. Forestry 45:67-86.

29. Van der Kamp, B. J. 1995. The spatial distribution of Armillaria root disease in an uneven-aged, spatially clumped Douglas-fir stand. Can. J. For. Res. 25:1008-1016.

30. Van der Pas, J. B. 1981. A statistical appraisal of Armillaria root in New Zealand plantations of Pinus radiata. N.Z. J. For. Sci. 11:23-36.

31. Van der Plank, J. E. 1963. Plant Disease: Epidemics and Control. Academic Press, New York.

32. Waring, R. H., Cromack, K., Matson, P. A., Boone, R. D., and Stafford, S. G. 1987. Responses to pathogen-induced disturbance: Decomposition, nutrient availability and tree vigour. Forestry 60:219-227. 